\title{
A COMUNICAÇÃO E A RELAÇÃO SOCIOCULTURAL DO ADORNO COMO OBJETO SIMBÓLICO DE UM HABITUS DE CLASSE
}

\author{
MARIA DA GRAÇA PORTELA LISBÔA \\ UNIVERSIDADE FEDERAL DE SANTA MARIA \\ SANTA MARIA, RIO GRANDE DO SUL, BRASIL \\ E-MAIL: MGLISBOA@YAHOO.COM.BR \\ CARLOS ORELLANA \\ UNIVERSIDADE FEDERAL DE SANTA MARIA \\ SANTA MARIA, RIO GRANDE DO SUL, BRASIL \\ E-MAIL: LAPISAZUL2984@YAHOO.COM.BR \\ ANDREA AD REGINATTO \\ CENTRO UNIVERSITÁRIO FRANCISCANO \\ SANTA MARIA, RIO GRANDE DO SUL, BRASIL \\ E-MAIL: ANDREA.REGINATTO@GMAI.COM
}




\section{A COMUNICAÇÃO E A RELAÇÃO SOCIOCULTURAL DO ADORNO COMO OBJETO SIMBÓLICO DE UM HABITUS DE CLASSE}

Resumo: A área da comunicação é campo de investigação científica para as questões de significação e culturais. A questão que norteia a presente pesquisa é como o adorno, entendido como simbólico ganha sentido dentro das disputas de classe por distinção. Há de se considerar que o peso dos diferentes agentes depende de seu capital simbólico, isto é, do reconhecimento, institucionalizado ou não, que recebem de um grupo. Palavras chave: Comunicação; Simbolismos; Habitus de classe; adorno

\section{COMUNICACIÓN Y RELACIÓN SOCIOCULTURAL DEL ADORNO COMO OBJETO SIMBÓLICO DE UN HABITUS DE CLASE}

Resumen: El área de la comunicación es campo de investigación científica sobre las cuestiones de significación y culturales. La pregunta que guía esta investigación es como el adorno, entendido como objeto simbólico, gana sentido dentro de disputas de clase por distinción. Tenemos que considerar que el peso de los diferentes agentes depende de su capital simbólico, es decir, del reconocimiento institucionalizado o no, recibido de un grupo. Palabras clave: Comunicación; Simbolismo; Habitus de clase; adorno

\section{COMMUNICATION AND SOCIOCULTURAL RELATIONS OF ADORNMENT AS SYMBOLIC OBJECT OF A CLASS HABITUS}

Abstract: The communication area is scientific research field to the signification and cultural issues. The question which guides this research is how the adornment, comprehended as symbolic issue, makes sense inside of class disputes for distinction. We consider that the weight of the different agents depends on their symbolic capital, for example, institutionalized recognition or not, received by a group. Keywords: Communication; Symbolism; Class habitus; adornment 


\section{INTRODUÇÃO}

O presente trabalho vale-se do extenso campo da Comunicação para compreender os simbolismos e os significados presentes nos adornos. Nesse sentido, busca verificar como é estabelecida a comunicação nas classes sociais em que estão inseridos, na medida em que sintetiza os principais aspectos sobre elaboração de significados e interações das estratégias de apresentação de si, mais precisamente o adorno numa concepção bourdiesiana.

Entendemos que o gosto, a escolha de objetos estéticos e as formas de apresentação de si são socialmente construídas, e acima de tudo, são constitutivas das classes sociais. Portanto, não podemos entender as lógicas dos bens simbólicos fora do contexto socialmente construído e na sua diferenciação e comunicação com as demais classes sociais.

Neste estudo, parte-se da noção de que a naturalização do gosto ou do padrão estético, nada mais é que uma estratégia de determinadas classes sociais na sua situação de disputa com as demais classes. Assim, entende-se que esse gosto não é universalmente distribuído, mas que está condicionado às condições nas quais os capitais econômico, cultural e social são distribuídos e negociados por meio de uma interlocução, via linguagem, com o outro nas relações socioculturais que se estabelecem, formando assim uma identidade.

Woodward (2000) diz que as identidades são fabricadas por meio da marcação da diferença. Essa marcação da diferença ocorre tanto por meio de sistemas simbólicos de representação quanto por meio de formas de exclusão social.

Para Oliven (2006, p. 34), as identidades são "construções sociais formuladas a partir de diferenças reais ou inventadas que operam como sinais diacríticos, isto é, sinais que conferem uma marca de distinção”. Assim, é possível entendermos a constante reconstrução da identidade, tendo em vista, principalmente, as trocas sociais que se configuram no meio. Por outras palavras, "a identidade (...) faz parte da complexidade do social. (...) Nenhum grupo, nenhum indivíduo está fechado a priori em uma unidimensional". (CUCHE, 1999, p. 192).

Se um dos pontos relevantes na identidade cultural é a diferença, é preciso considerar ainda que há uma complexidade social que: 
A comunicação e a relação sociocultural do adorno como objeto simbólico de um habitus de classe

Cada indivíduo integra, de maneira sintética, a pluralidade das referências identificatórias que estão ligadas à sua história. (...) Cada indivíduo tem consciência de ter uma identidade de forma variável, de acordo com as dimensões do grupo social ao qual ele faz referência em tal ou tal situação relacional (CUCHE, 1999, p. 194).

Para Hall (1996, p. 69), "As identidades culturais provem de alguma parte, têm histórias. Mas, como tudo o que é histórico, sofrem transformação constante". Assim, para o autor, não é possível determinar a identidade cultural em si mesma e deforma definitiva.

\section{DESENVOLVIMENTO}

Para a compreensão deste estudo, é importante buscarmos na linguagem do tempo qual a comunicação que se estabelece com o homem e o uso dos adornos, além de fazermos uma recuperação histórica, mesmo que breve, sobre a importância do adorno na sociedade e seu simbolismo. Para tanto, vale-se principalmente dos autores Baudrillard (1970), Bourdieu (2008), Gourham (1983) e Codina (2000).

Nesse sentido, a fim de elucidar questões importantes para este trabalho, busca-se discutir os bens simbólicos, a partir do entendimento de seu contexto socialmente construído, assim como de sua diferenciação com as demais classes sociais. É imprescindível entender as lógicas da questão de gosto, a escolha de adornos estéticos e as formas de apresentação de si que são socialmente construídas e constitutivas das classes sociais.

A naturalização do gosto ou do padrão estético, nada mais é que uma estratégia de diferenciação entre as classes, e esse gosto não é universalmente distribuído, mas está condicionado às condições nas quais os capitais (econômico, cultural e social) são distribuídos e negociados. Para a compreensão deste estudo, é importante identificarmos a relação que se estabelece entre o homem e o uso dos adornos.

A busca nos remete às manifestações do homem pré-histórico em relação ao seu enfeite pessoal e sua primitiva indústria - épocas superiores do Paleolítico, ou seja, da Idade da Pedra lascada. A literatura nos mostra que o homem dessa época tenta recorrer a um princípio de objetos de fácil manipulação, que a mesma natureza lhe oferece prodigamente.

Gourham (1983) analisa a forma do adorno primitivo e sua relação de uso também na contemporaneidade, ao afirmar que: 
(...) se ao lado das conchas perfuradas, se encontram pedras de formas curiosas, bocados de minerais, amostras de cristal de rocha, pode-se pensar que os homens recolhiam estes objetos porque os consideravam belos e lhes atribuíam propriedades mágicas, esta dupla preocupação encontra-se nos povos atuais, que fazem coleções do mesmo gênero. (GOURHAM, 1983, p 64.)

O referido autor permite refletir acerca dessa estética e dos simbolismos atribuídos aos adornos na contemporaneidade, os quais vêm desde os primórdios do homem, posto que ele já demonstrava a sensibilidade para o belo e atribuía significados às coisas que criava para enfeitar-se. Assim, ao estudar os adornos em um programa televisivo, por exemplo, é possível compreender o comportamento do homem contemporâneo e das relações sociais e culturais que se estabelecem na sociedade.

E nessa ótica o design como uma atividade criativa corrobora na criação de objetos com qualidades multifacetadas, processos e serviços e seus sistemas em ciclos de vida completos. Sendo o design fator central da humanização inovadora de tecnologias e o fator crucial do intercâmbio cultural e Econômico (MOZOTA, 2011).

$O$ design junto à comunicação trata-se de um campo de pesquisa que compreende as investigações científicas relativas às questões de construção de significação e apelos culturais identitários da sociedade na moda. De modo que, a influência da mídia no comportamento das pessoas que consomem bens culturais e se inspira nos conteúdos apresentados pelas diversas mídias, em especial a televisão, para desejar os objetos/serviços.

Para Martino (2005, p. 43). Este universo simbólico da sociedade é, via de regra, influenciado pela mídia. Quanto maior o tempo de exposição à mídia, maior sua influência na definição de consumo. Não apenas o consumo simbólico, mas também a posse material de bens de consumo é carregada de simbolismos e serve como mediação das relações sociais. O dado pode ser empiricamente comprovado pela visibilidade social dos produtos divulgados na televisão. Nesse sentido, observa-se a influência da TV no comportamento do telespectador caracterizada nos lançamentos de coleções de joias que os artistas, e apresentadores de programas usam e desse modo motivam o espectador a usá-los. Constituindo assim, na imagem simbólica veiculada, a estética e a ressignificação, como um disseminador da moda.

Para Baudrillard (1970) o consumo dos objetos se dá quando se estabelece uma relação entre o indivíduo e significado do objeto, com uma 
A comunicação e a relação sociocultural do adorno como objeto simbólico de um habitus de classe

dupla função: "uma que é a de ser utilizado e, a outra, é a de ser possuído". Entende-se aqui a posse de um objeto abstraído de sua função e relacionado ao indivíduo, pois ao considera o aspecto simbólico e subjetivo dos adornos criados para representação de si, é possível incluí-los na referida categoria.

A sociedade contemporânea é regida pela cultura do consumo de massa, que se esconde atrás do produto personalizado. Do ponto de vista do poder hegemônico, as subjetividades precisam com urgência aderir aos valores do consumo sendo os produtos excelentes fontes de informação sobre as pessoas que os consomem. As escolhas do consumidor são feitas por várias razões não tão fáceis de prever e de compreender (CSIKSZENTMIHALYI, 2000), mas frequentemente, o consumidor se vale do significado social dos produtos para moldar sua própria imagem (SOLOMON, 2002) e fala sobre si mesmo por meio dos bens personalizados que consome.

Com o surgimento da sociedade de consumo, os bens passam a depender mais do seu significado social do que de sua utilidade funcional. $O$ simbolismo contido nos produtos tornou-se o principal combustível para sua compra e uso. Assim como a escolha por produtos ou marcas, o consumo é regido por códigos que enfatizam a análise e a relação entre os objetos (SOLOMON, 2002).

Desse modo, podemos entender que cada traço de maquiagem, corte de cabelo, joias, arrumações estéticas em geral ou atitudes de cuidados pessoais com a beleza refletem um pouco do que somos e um pouco do que queremos ser. Pela sua aparência, uma pessoa diz a que grupo ela pertence ou até aos quais ela não pertence. Ou seja, o indivíduo gerencia o seu corpo de acordo com a forma como ele deseja ser visto e enquadrado na sociedade. O corpo humano é considerado um depositário da cultura do indivíduo, "um prolongamento de nós mesmos" (KURY, HARGREAVES \& VALENÇA, 2000).

O significado dos bens de consumo está na sua habilidade de carregar e comunicar um valor cultural (MCCRACKEN, 1986). A cultura permite que o consumidor se coloque no lugar do outro e enxergue a si mesmo da mesma forma que os outros.

Se nos reportarmos à evolução dos adornos em Gourhan (1983), encontramos o Período Neolítico com importantes acontecimentos e inventos de novas técnicas e materiais na fabricação de armas, utensílios, adornos. Isso variava de região para região em função da existência natural e do progresso de intercâmbio exercido entre os povos. Dessa forma, percebe-se 
a cultura como fenômeno regional, definidora de certos costumes e sua importância para compreender os significados dos hábitos e dos costumes que os elementos culturais materiais e imateriais fornecem aos múltiplos contextos sociais.

De acordo com Codina (2000) na Idade dos Metais, o homem amontoava sobre suas roupagens toda classe de objetos metálicos como fivelas, alfinetes e botões de bronze. Contudo, o que observamos é o simbolismo atribuído ao ouro desde o ancestral do homem moderno, no uso de adornos e sua relação com as crenças que percorre caminhos e fundamentos de diferentes culturas.

Na Idade Antiga, o trabalho de ourivesaria dos celtas se constitui como um dos mais importantes e, por essa razão, é adotado pelos mais diversos povos. Acerca disso Subirachs (1996, p. 30), afirma: "a luxuosa arte dos Celtas compreendia desde arreios e bridas de cavalos, como carros de combate, espadas e punhais, máscaras e peças de bronze originais e importadas de outras regiões." O referenciado autor esclarece ainda que os Celtas não eram um povo unificado, mas sim tribos homogêneas pelo parentesco e por um habitat e costumes comuns, que povoavam o centro da Europa constituindo um agrupamento de sociedades. Ao analisar essa questão, é possível promover uma interlocução com o estudo dos hábitos e costumes da cultura do gaúcho, que tem forte apego ao cavalo, uma vez que isso pode encontrar raízes na cultura Celta.

Nesse sentido, a representação e a significação dos adornos mudaram com o tempo, pois se reinventam e adquirem novos sentidos. Para Codina (2000), o impacto da Revolução Industrial sobre a sociedade europeia foi expresso pelo crescente gosto pelo luxo, encorajado pelo período de prosperidade que se vivia, perdurando até o século $\mathrm{XX}$, quando perde as conotações de ostentação e riqueza com joias de desenhos simples e elegantes. De um lado a joia voltada para a moda e o desenho industrial objetivando o mercado. De outro, a joia orientada para a arte como forma de expressão pessoal, que procura cumplicidade com o usuário. Trata-se de uma joalheria que tenta traduzir os valores simbólicos e espirituais que caracterizam a sociedade tecnológica do novo milênio.

Para Baudrillard (1970) o adorno pode ser entendido como objeto simbólico que ganha autonomia em relação ao modo de produção e de apropriação, além de uma dimensão de independência, que se configura como um espaço simbólico fechado. A contribuição do autor é importante, pois 
A comunicação e a relação sociocultural do adorno como objeto simbólico de um habitus de classe

concebe o objeto em uma dupla dimensão: instrumento e signo.

Ao apresentar um histórico da lógica de produção e de apropriação de um bem simbólico, "o adorno", deseja-se refazer o percurso pelo qual o adorno é apropriado pelo homem, especificamente, pela cultura e pelas forças materiais (classe, capital material e imaterial) que vão integrar esse objeto no campo de bens simbólicos.

Bourdieu (2008), afirma que os discursos alcançam seu valor e seu sentido apenas através da relação com seu mercado, pois o valor do discurso depende das relações de força que se estabelecem concretamente entre as competências estéticas dos agentes, que são entendidas ao mesmo tempo como capacidade de produção, de apropriação e de apreciação, pois se trata de capacidades de produção socialmente classificadas, o que torna o adorno objeto simbólico que adquire sentido dentro das disputas de classe por distinção. Trata-se, então, do peso dos diferentes agentes depende de seu capital simbólico, isto é, do reconhecimento, institucionalizado ou não, que recebem de um grupo: a imposição simbólica. Uma espécie de eficácia mágica, cuja ordem ou a palavra de ordem, o discurso ritual ou a simples injunção, só podem funcionar enquanto tal quando estiverem reunidas as condições sociais inteiramente externas à lógica propriamente discursiva.

Bourdieu (2008) compreende que os bens culturais possuem uma economia própria, além de que muitas vezes tentam se apresentar como espaço de subjetividade, mas que na verdade esconde uma série de disputas, ideologias e diferenças sociais, que por sua vez determinam a economia dos bens simbólicos.

É necessário enfatizar que o autor supracitado considera que tanto o agente como o campo (espaço social de autonomia relativa que controla certo domínio do saber) se constituem, ou seja, não há uma determinação puramente do social sobre o individual. Nas palavras bourdieusianas, a estrutura pode ser uma estrutura estruturada e uma estrutura estruturante que correspondem respectivamente a um conjunto de disposições sobre as quais os indivíduos não detêm autonomia (língua, classe, gênero) e o segundo refere-se a disposições mais ou menos capazes de serem investidas pelos indivíduos para que possam modificá-las (estilo de vida, gosto, comportamento).

Entender o conceito de habitus é oportuno para compreender como o adorno e as relações sociais que o definem fazem sentido ao indivíduo e à sociedade. Nessa ótica o habitus corresponde a um conceito que surge da 
necessidade de entender os modos pelos quais certas disposições e esquemas de classe são incorporados a práticas cotidianas dos indivíduos, isto é, apreende-se esse conceito como a lógica específica de articulação do individual e do coletivo.

Bourdieu (2008), apresenta o habitus como uma estrutura interna sempre em via de reestruturação. Isso corresponde à ideia que ela se dá em etapas e que ela se ajusta a novas situações. A primeira etapa de socialização é denominada de habitus primário como conjunto de ações, pensamentos, palavras adquiridas no grupo familiar que interiorizamos certas propriedades ligadas às condições sociais de nossos pais. A segunda etapa considerada como habitus secundários o conjunto de esquema de percepção que se sobrepõe ao primeiro habitus. Nessa segunda fase, o habitus escolar tende a continuar e redobrar o habitus primário. Essa articulação de conceitos e etapas resulta no desenvolvimento da ideia de que a personalidade individual acaba por ser uma variante do habitus de classe. Assim, o habitus será uma das forças reprodutoras do gosto ou do estilo de vida, e o adorno será a materialização de uma série de capitais desigualmente distribuídos.

Portanto, a apreciação dos objetos simbólicos é guiada por duas forças que se constituem dentro do campo de bens simbólicos, uma é o habitus primário, isto é, a família e sua posição de classe que configura as percepções ou gosto dos indivíduos como forma de reprodução de um gosto de classe. A segunda é a lógica própria dos bens culturais, ou seja, o mercado de bens culturais.

\section{CONCLUSÃO}

Entendemos o adorno como um objeto eficaz na estratégia de distinção social produzidas pelas classes mais altas e afirmação do seu estilo de vida distintivo e fora das pressões materiais mais simples na medida em que sua dimensão de produção, consumo e distribuição está ligada fortemente a ideia de disposição estética pela qual muitas outras classes não estariam no mesmo patamar de apreciação.

A imagem simbólica para o receptor constitui funções simbólicas intrínsecas, inerentes ou associadas aos objetos, reflete os contextos sociais, econômicos e culturais do design. Sendo o produto incorporado ao estilo de vida e certos valores culturais de pessoas e grupos sociais, conectadas a determinadas características sensíveis e emocionais do usuário. 
A comunicação e a relação sociocultural do adorno como objeto simbólico de um habitus de classe

No Signo podemos representar algo que entre si, se organiza e forma sistemas de linguagem. No adorno encontra-se a comunicação estética no conjunto de elementos como a forma, cor, material, entre outros que forma os valores emocionais de que os produtos são portadores.

A Comunicação se presta ao aprofundamento na continuidade da pesquisa empírica para levantar questionamentos relevantes para compreensão das diferenças na apropriação de bens simbólicos. 


\section{REFERÊNCIAS}

BAUDRILLARD, J. 1970, The Consumer Society: Myths and Structures, 1st edn, Sage Publications Ltd, 1998, London.

BOURDIEU, Pierre. Economia das trocas simbólicas. São Paulo Perspectiva, 1974. . Economia das trocas linguísticas. São Paulo: Edusp, 1996.

. A distinção: crítica social do julgamento. São Paulo: Edusp, 2008.

CELORIA, Francis. A joalheria. Traduzido por Marisa Costa. Lisboa: Editorial Estampa, Ltda, 2000.

CODINA, Carles. Arqueologia. Trad. Fernando de Castro Ferro. São Paulo: Edições Melhoramentos/Edusp, 1970.

. A ourivesaria. Trad. Marisa Costa. Lisboa: Editorial Estampa Ltda. 2002. (Coleção

Artes e Ofícios).

CUCHE, Denys. A noção de cultura nas ciências sociais. Bauru: EDUSC, 1999.

CSIKSZENTMIHALYI, M. The Costs and Benefits of Consuming, Journal of Consumer Research, v. 27, September/2000.

GIORDANI, Mário Curtis. História da antiguidade oriental. 6. ed. Petrópolis: Editora VOZES, 1983.

GOURHAN, André Leroi. Os caçadores da pré-história. Lisboa, Portugal: Ed. 70, 1983. v. 22.

KERTESZ, Margarite W. Historia universal de las joyas atraves del arte y la cultura. Buenos Aires: Centurion, 1947.

KURY, M.T; HARGREAVES, L; VALENÇA, M.T. Ritos do Corpo. Rio de Janeiro. Ed. Senac Nacional, 2000.

MARTINO, L.M.S. Comunicação: troca cultural? São Paulo: Paulus, 2005.

MCCRACKEN, G. Culture and consumption: a theoretical account of the structure and movement of the cultural meaning of consumer goods, Journal of Consumer Research, $v$ 13, June /1986.

MOZOTA, Borja de; Klöpsch, C. and Costa, F.C.X. Gestão do design: usando o design para construir valor de marca e inovação corporativa. Tradução: Lene Belon Ribeiro, Porto Alegre: Bookman, 2011

SANTAELLA, Lucia. Culturas e artes do pós-humano: da cultura das mídias a cibercultura. São Paulo, SP: 2003

SUBIRACHS, Josep Maria. História Geral da Arte. Madrid: Ediciones Del Prado, 1996.

SOLOMON, M. O Comportamento do consumidor: comprando, possuindo, sendo. 5. ed. Porto Alegre: Bookman, 2002.

OLIVEN, Ruben George. A parte e o todo: a diversidade cultural no Brasil-nação. Petrópolis, RJ: Vozes, 1992 (2006). 
A comunicação e a relação sociocultural do adorno como objeto simbólico de um habitus de classe

\section{Andrea Ad Reginato}

Doutora em Letras/Linguística na Pontifícia Universidade Católica do Rio Grande do Sul. Possui graduação em Letras pelo Centro Universitário Franciscano (1996), especialização em Língua Portuguesa e Literatura Brasileira pelo Centro Universitário Fransicano(1997) e mestrado em Letras pela Pontifícia Universidade Católica do Rio Grande do Sul (2000). Atualmente é professora no Centro Universitário Franciscano e na Faculdade Metodista de Santa Maria. Atua como professor/ pesquisador na UAB/UFSM/EaD no Curso de Letras - Português. E-mail: andrea.reginatto@gmai.com

\section{Carlos Alberto Orellana Gonçalves}

Doutorando visitante da Sorbonne Paris III com orientação do prof François Jost. Doutorando do Programa de Pós-Graduação em Comunicação (POSCOM) da Universidade Federal de Santa Maria (UFSM) na linha de pesquisa de Mídias e Identidades Contemporâneas sob a orientação da Profa. Dra. Ada Cristina Machado Silveira, bolsista da Coordenação de Aperfeiçoamento de Pessoal de Nível Superior (CAPES), mestre e bacharel em Comunicação Social (com habilitação em Jornalismo) pela Universidade Federal de Santa Maria (UFSM). Fundador do aplicativo ROOM Education.E-mail: lapisazul2984@yahoo.com.br

\section{Maria da Graça Portela Lisboa}

Mestre em Engenharia da Produção pela Universidade Federal de Santa Maria - RS. No mestrado trabalhou com a temática do design e da qualidade através da análise da cadeia produtiva da ourivesaria da região central do Rio Grande do Sul. Bacharel em Design de Produto com ênfase em joias pelo Centro Universitário Franciscano. Coordenadora do Curso Superior Tecnológico em Design de Moda e Docente do Curso de Design de Produto do Centro Universitário Franciscano. Pesquisadora do Grupo de Pesquisa Design e Gestão do Produto, na linha de pesquisa História, Estética e Cultura 
dos Objetos do Centro Universitário Franciscano (UNIFRA). E-mail:mglisboa@unifra.br/mglisboa@yahoo.com.br

Artigo recebido em 06/10/2016

Aceito em 07/12/2016 